\title{
PENERAPAN ASUHAN KEPERAWATAN PADA PASIEN Tn.M DENGAN PRE OPERASI BENIGNA PROSTATE HIPERPALSIA ( BPH ) DALAM PEMENUHAN KEBUTUHAN RASA AMAN DAN NYAMAN DI RUANG TULIP DI RS TK II PELAMONIA MAKASSAR \\ Application Of Nursing Care To Patients. M With Preoperative Benign Prostate Hiperplasia ( Bph ) In Meeting The Needs Of Safe And Comfortable Feeling In Yhe Tulips Room Tk li Pelamonia Makassar
}

\author{
HARMAWATI \\ Program Studi D3 Keperawatan Universitas Muhammadiyah Makassar
}

\begin{abstract}
ABSTRAK
Pendahuluan : Benign Prostate Hiperpalsia adalah suatu penyakit pembesaran prostat atau hipertropi yang pembesarannya progresif dari kelenjar prostat. Tujuan : Untuk melaksanakan Asuhan Keperawatan Kebutuhan Rasa Aman dan Nyaman pada pasienPre Operasi Benign Prostate Hiperplasia (BPH) . Metode : Metode yang di gunakan dalam penyusunan Karya Tulis IImiah adalah metode deskriptif.. Data yang diperoleh dari pasien, keluarga, perawat, tim kesehatan, dan catatan medic . Hasil : Masalah pasien belum teratasi. Kesimpulan : Dari penangan rasa aman dan nyaman yang dilakukan pada pasien Pre Operasi Benign Prostate Hiperplasia (BPH) dapat terpenuhi.
\end{abstract}

Kata Kunci : Benign Prostate Hiperplasia, Pre operasi, Rasa Aman dan Nyaman

\section{ABSTRACT}

Introduction: Benign Prostate Hyperpalsia is a prostate or hypertrophic enlargement disease whose progressive enlargement of the prostate gland.. Objective: To implement Nursing Care for Safe and Comfortable Needs in patientsPre Operation of Benign Prostate Hyperplasia (BPH) in accordance with nursing standards. Method: The method used in the preparation of Scientific Writing is a descriptive method, with a case study approach. Data obtained from patients, patients' wives, , nurses, health teams, nursing records, records. Results: After $2 \times 24$ hours of nursing action the patient's safe and comfortable feeling has not been resolved. Conclusion: From safe and comfortable safety handlers performed on Pre Preoperative Benign Prostate Hyperplasia (BPH) patients can be fulfilled.

Keywords: Benign Prostate Hyperplasia, Pre operation, Safe and Comfortable

\section{PENDAHULUAN}

Marilynn ( 2000 ) dalam Rudi Hariono ( 2013 ) mengatakan bahwa Benign Prostate Hiperplasia adalah pembesaran progresif dari kelenjar prostat ( secara umum pada pria lebih tua dari 50 tahun ) menyebabkan berbagai derajat obstruksi aliran urinarius. Benign Prostate Hiperplsasia (BPH) adalah suatu masalah yang akhir-akhir ini sering terjadi pada pria lebih tua dari 50 tahun karena sering menahan air kencing pada saat ingin berkemih, sehingga terjadi suatu pembesaran progresif dari kelenjar prostat menyebabkan berbagai derajat obstruksi aliran urinarius.

Raharjo ( 2013 ) mengemukakan angka kejadian Benign Prostate Hiperplsasia (BPH) di Indonesia, bervariasi $24-30 \%$ dari kasus urologi yang dirawat dibeberapa rumah sakit. Tahun 1994-1997, Berdasarkan statistik di negara jepang pada tahun 2004 , memperkirakan terdapat sekitar 70 juta kasus degeneratif pada tahun 2015. Salah satunya adalah BPH dengan kisaran antara 70.000 kasus, dengan insidensi di negara maju sebanyak $19 \%$, sedangkan di negara berkembang sebanyak $5,35 \%$ kasus. Yang ditemuka pada pria dengan usia lebih dari 65 tahun dan dilakukan pembedahan setiap tahunnya. Tingginya kejadian BPH di indonesia telah menempatkan BPH sebagai penyebab angka kesakitan nomor 2 terbanyak setelah penyakit batu pada saluran kemih. (Suzuki, 2009)

Apabila masalah ini tidak ditangani maka nyeri akan semakin meningkat dan penderita Benign Prostate Hiperplasia ( BPH ) tidak bisa mengerluarkan air kencing ( miksi ) secara normal karena saluran kemih mengalami penyumbatan. Nyeri adalah gejala subjektif, hanya klien yang dapat mendeskripsikannya. Nyeri tidak dapat diukur secara objektif oleh praktisi kesehatan. Seorang ahli teori nyeri yang terkenal, Margo McCaffery, mengataan dalam makalah klasiknya bahwa, "Nyeri adalah apa pun yang di katakan oleh individu yang mengalami sebagai nyeri,ada kapan pun individu tersebut mengatakan ada. (Caroline, B , 2015)

Summer ( 1985 ) dalam Palapina Heriana (2014) mengatakan Nyeri adalah suatu perasaan yang tidak mengenakan dan disebabkan oleh stimulus spesifik 
seperti : mekanik, termal,kimia,mikroorganisme atau elektrik pada ujung saraf serta tidak dapat diserahterimakan kedapa orang lain.

Berdasakan hasil uraian latar belakang diatas, maka penulis tertarik untuk melakukan studi kasus dengan judul" Penerapan Asuhan Keperawatan Kebutuhan Rasa Aman dan Nyaman pada pasien Benign Prostate Adapun tujuan dari penelitian studi kasus ini adalah Menggambarkan Asuhan Keperawatan Kebutuhan Rasa Aman dan Nyaman pada pasien Benign Prostate Hiperplasia (BPH).

\section{METODE PENELITIAN}

\section{Rencana Studi Kasus}

Metode deskriptif yaitu suatu metode yang mengungkapkan peristiwa atau gejala yang terjadi pada waktu sekarang meliputi metode penulisan, teknik pempulan data, sumber data, studi kepustakaan yang mempelajari, mengumpulkan, membahas dan dengan studi pendekatan proses keperawtan dengan langkahlangkah pengkajian, diagnosa, perencanaan, pelaksaan dan evaluasi.

\section{Subyek Studi Kasus}

Subyek yang digunakan pada studi kasus ini adalah laki-laki dewasa dan lansia dengan penyakit Benigna prostat hiperplasia dengan masalah keperawatan kebutuhan gangguan rasa aman dan nyaman (nyeri akut).

1. Kriteria Inklusi
a. Pasien dengan berjenis kelamin laki-laki.
b. Derajat stadium II
c. Pasien berusia $\geq 45$ tahun.
d. Tidak ada gangguan komunikasi.
e. Pasien dengan diagnosa medis BPH ( Pre op)
f. Bersedia menjadi responden.
g. Pasien dengan BPH yang mengalami maslah kebutuhan rasa aman dan nyaman.

\section{Kriteria Ekslusi}
a. Pasien berusia $\leq 45$ tahun.
b. Tidak dapat berkomunikasi.
c. Pasien dengan diagnosa medis BPH ( Post op)
d. Tidak bersedia menjadi responden

\section{Fokus studi}

Kajian utama studi kasus ini adalah asuhan keperawatan dan yang menjadi titik acuan setelah diterapkannya proses Asuhan Keperawatan tersebut adalah dengan membandingkan perbedaan yang terjadi pada 2 pasien Benigna Prostat Hyperplasia ( $\mathrm{BPH}$ ) dengan masalah keperawatan Kebutuhan Rasa Aman dan Nyaman (Nyeri).

\section{Instrument Studi Kasus}

Instrument penelitian yang dimaksud adalah format pengkajian dan pedoman wawancara

\section{Metode pengumpulan data}

Metode yang digunakan penulis dalam pengumpulan data pada penelitian ini meliputi wawancara, observasi, dan dokumentasi. Metode wawancara dilakukan untuk mengetahui keluhan utama, riwayat keluhan utama, dan riwayat kebiasaan seharihari klien. Hal tersebut dibuktikan pada pemeriksaan fisik yang digunakan sebagai penunjang atas keluhankeluhan yang disampaikan klien. Sedangkan dokumentasi merupakan data pribadi klien yang meliputi nama, umur, jenis kelamin, nomor rekam medik, dan lain sebagainya.

\section{Lokasi dan waktu penelitian}

Penelitian dilakukan di pada hari Senin sampai dengan Sabtu, 26 s/d 27 Juli 2017 di RS TK. II Pelamonia Makassar.

\section{Penyajian data}

Data yang diperoleh kemudian dikumpulkan dan disajikan dalam bentuk asuhan keperawatan yang berisikan satuan jumlah maupun pernyataan verbal dari subyek sebagai data pendukung.

\section{Hasil Studi Kasus}

1. Data yang diperoleh kemudian dinarasikan.

Pengkajian dilakukan dengan metode autonamnesa atau pengkajian yang dilakukan dengan metode wawancara lansung kepada klien dan pengkajian dengan melihat berdasarkan data dalam status klien dan dari keluarga.

Pasien bernama Tn. M, umur 77 tahun, alamat JI. A. Mappanyukki Kompleks PA .V/ K28, pendidikan terakhir klien adalah SMA, agama islam, suku bugis, Status Menikah, informan pasien dan keluarga, nomor rekam medik 128168 , tanggal masuk 25 Juli 2017, pengkajian dilakukan pada tanggal 26 Juli 2017, pasien merupakan pensiunan TNI AD Kodam XIV Hasanuddin.

Keluhan utama yang dirasakan klien adalah nyeri jika berkemih dan sering buang air kencing pada malam hari. Adapun Prokatif $(P)$ : nyeri pada saat berkemih, Qualitas (Q) : seperti ditusuk-tusuk, Region (R): di buli-buli, Skala (S) : setiap malam 7-8 ,Timing (T) : 5 bulan yang lalu. Aktivitas pasien sangat aktif dan masih sering sering ikut senam jantung dan merupakan salah satu penggas senam jantung sehat di stadion Andi Mattalata kota Makassar, makan dan minum pasien terlihat masih 
lancar dan tidak membutuhkan bantuan keluarga. Klien mengatakan pernah di rawat di rumah sakit pelamonia dengan penyakit yang sama dan pernah dilakukan tindakan operasi pembedahan karna penyakit Benign Prostate Hiperpalsia ( BPH ) pada tahun 2015. Klien mengatakan tidak ada keluarga yang menderita penyakit yang sama.

Hasil pengkajian pemeriksaan fisik pasien pertama didapatkan data : Berat Badan $70 \mathrm{~kg}$, Tinggi Badan $173 \mathrm{~cm}$. Pemeriksaan tanda-tanda vital, Tekanan Darah 130/80 mmhg, suhu $36,2^{\circ} \mathrm{C}$, pernafasan 20 kali permenit, nadi 80 kali permenit. Pada pemeriksaan umum kesadaran klien adalah composmentis. Turgor kulit elastis. Mukosa mulut kering, rambut bersih, hitam, kongjungtiva anemis, mata cekung, lidah bersih, kuku bersih.

Hasil Pemeriksaan Penunjang yang didapatkan adalah tes lab. Pada tanggal 25 juli 2017 dengan hasil : Glukosa sewaktu $87 \mathrm{mg} / \mathrm{dl}$, ureum $48 \mathrm{mg} / \mathrm{dl}$, kreatinin 1,3* $\mathrm{mg} / \mathrm{dl}$, total PSA 1,42 $\mathrm{ng} / \mathrm{ml}$. Terapi obat yang diberikan injeksi ceftriaxone $2 \times 3$, ketorolak $2 \times 3$, terpasang infus intravena RL $28 \mathrm{tpm}$. Dan hasil foto thorax pada tanggal 26 Juli 2017 yaitu tidak tampak kelainan pada foto thorax ini. Wires terpasang pada sternum.

Dari data hasil pengkajian dan observasi tersebut diatas, penulis melakukan analisa data, kemudian membuat prioritas diagnosa keperawatan sesuai dengan masalah keperawatan yang dialami pasien atau yang harus segera dilakukan penanganan segera.

Adapun prioritas masalahnya yakni Gangguan rasa nyaman nyeri sehubungan dengan retensi urine. Data yang menunjang diagnosa keperawatan tersebut adalah data subyektif klien mengeluh nyeri, klien mengatakan sering kencing tengah malam, ketika buang air kecil terasa panas, nyeri daerah pinggang . Data Obyektif klien nampak meringis, ekspresi wajah meringis, tanda-tanda vital TD 130/80 mmhg.

Penulis akan membahas rencana keperawatan sesuai dengan prioritas masalah pada pasien. Rencana keperawatan dengan tujuan keperawatan setelah dilakukan tindakan keperawatan selama 2x24 jam diharapkan Nyeri teratasi dengan kriteria hasil nyeri berkurang, pasien nampak rileks, TTV dalam batas normal tekanan darah $120 / 80 \mathrm{mmHg}$, nadi 80-100 kali permenit, pernafasan $18-20$ kali permenit, suhu $36-37^{\circ} \mathrm{C}$.

Intervensi yang dibuat berdasarkan diagnosa keperawatan adalah mengkaji nyeri rasionalnya mengetahui daerah nyeri, kualitas nyeri, kapan nyeri dirasakan, faktor pencetus, berat ringanya nyeri yang dirasakan. Observasi TTV rasionalnya untuk mengetahui keadaan umum pasien. Ajarkan teknik relaksasi nafas dalam rasionalnya untuk mengajarkan pasien mengatasi nyeri apa bila nyeri timbul. Berikan posisi Rasionalnya posisi yang yang nyaman akan membantu memberikan kesempatan pada otot untuk relaksasi seoptimal mungkin. Kolaborasi dengan dokter dalam pemberian antibiotik Rasional untuk membantu mengurangi nyeri pada pasien. pemberian obat penghilang nyeri.

\section{Pembahasan}

Pada kasus Tn. M ditemukan data nyeri yang mana sesuai dengan pengkajian dan teori yang tercantum dalam buku (Saputra, 2013)

Menurut (Padila, 2012), diagnosa yang dapat muncul pada pre operasi yaitu :

a. Gangguan rasa nyaman nyeri sehubungan dengan retensi urine.

b. Perubahan eliminasi urine : retensi urine sehubungan dengan obstruksi mekanik, pembesaran prostat dan ketidakmampuan kandung kemih berkontraksi lebih kuat.

c. Resiko infeksi sehubungan dengan retensi urine dan terpasangnya dower kateter

d. Ansietas sehubungan dengan prosedur pembedahan

e. Kurang pengetahuan tentang proses penyakit, tanda dan gejala serta perawatan dirumah sehubungan dengan kurang informasi.

Rencana keperawatan pada kasus Tn.M telah sesuai dengan intervensi keperawatan menurut Padila ( 2012 ). Dari 7 intervensi yang ada dalam teori Padila ( 2012 ) , hanya 5 intervensi yang terlaksana. Dua intervensi yang tidak terlaksana yaitu meningkatkan relaksasi tidak di laksanakan karena pasien merasa masih bisa melakukan aktivitas dan merasa otot-ototnya tidak kaku dan yang kedua yaitu tirah baring tidak dilaksanakan karena klien merasa tidak terlalu suka untuk tidur di tempat tidur dan pada saat pengkajian klien sedang membaca surat kabar sambil duduk di kursi, selain itu Pasien Tn.M pernah diajarkan oleh perawat yang bertugas pada waktu tersebut sehingga pasien mengerti tentang tindakan yang akan di lakukan pada penyakit yang dialami. Selain itu tidak di temukan demam dalam pengkajian akan tetapi dalam teori Padila ( 2012 ) terdapat. Demam terjadi di Benign Prostat Hiperpalsia karena terjadinya infeksi apabila telah dilakukan tindakan operasi.

Implementasi yang dilaksanakan berdasarkan intervensi yang telah ditetapkan oleh penulis. 


\begin{abstract}
Evaluasi keperawatan pada kasus Tn.M masalah belum teratasi dikarenakan menurut Rosdhal dan Bunker, C (2015) skala nyeri 1-10 sedangkan nyeri yang dirasakan Tn. M adalah 8 karena telah diajarkan teknik untuk mengurangi rasa nyeri sehingga pada saat evaluasi turun menjadi 5.
\end{abstract}

\section{Kesimpulan}

1. Pengkajian keperawatan merupakan tahap awal dalam proses keperawatan yang dilakukan untuk mendapatkan data awal yang selanjutnya dapat digunakan untuk menegakkan diagnosa, menyusun intervensi keperawatan, implementasi dan mengevaluasi tindakan yang dilakukan sehingga pelayanan keperawatan pada pasien dapat dilakukan secara optimal.

2. Penulis menegakkan diagnosa keperawatan sesuai dengan data-data yang didapatkan berdasarkan hasil pengkajian dan direlevankan dengan teori yang telah ditetapkan. Diagnosa keperawatan yang muncul pada Tn. M adalah Gangguan Rasa Nyaman Nyeri Sehubungan dengan retensi Urine.

3. Rencana tindakan pada pada kasus Tn. M dengan Gangguan Rasa Nyaman Nyeri Sehubungan dengan retensi Urine disusun sesuai teori dari diagnosa keperawatan yang muncul.

4. Dalam pelaksanaan tindakan keperawatan pada kasus Tn. M dilakukan sesuai dengan rencana keperawatan yang telah ditetapkan.

5. Evaluasi keperawatan dilakukan dengan cara mengidentifikasi sejauh mana hasil dari tindakan keperawatan yang dilakukan tercapai dengan merujuk pada tujuan dan kriteria hasil yang telah ditetapkan. setelah melakukan asuhan keperawatan pada kasus Tn. M, Masalah keperawatan nyeri belum teratasi yang dibuktikan dengan klien masih merasakan nyeri pada bagian perkemihan, nyeri dari 8 menjadi 5 , nyeri terasa saat klien ingin buang air kecil.

\section{Saran}

1. Penulis menyarankan dalam melakukan pengkajian keperawatan peneliti perlu mengupayakan agar pengkajian keperawatan dilaksanakan secara sistematis sesuai dengan konsep dan menggunakan komunikasi terapeutik sehingga data didapatkan akurat dan memudahkan dalam menentukan masalah yang ada pada klien.

2. Dalam merumuskan diagnosa keperawatan hendaknya dirumuskan berdasarkan pengkajian dan diprioritaskan sesuai dengan tingkatan kebutuhan klien.

3. Dalam menetapkan perencanaan keperawatan harus sesuai dengan masalah yang muncul pada klien dan melibatkan keluarga dan tim kesehatan lainnya agar penerapan rencana keperawatan benar-benar sesuai dengan kebutuhan klien.

4. Dalam pelaksanaan asuhan keperawatan, klien dan keluarga perlu dilibatkan secara aktif dan tetap menjalin kerja sama dengan tim kesehatan untuk mendapatkan hasil yang optimal.

5. Evaluasi

6. Evaluasi keperawatan hendaknya dilakukan secara bertahap sesuai dengan kondisi klien dan tetap diarahkan sesuai dengan tujuan yang telah ditetapkan.

\section{DAFTAR PUSTAKA}

Amin Huda Nurarif, \& Hardhi Kusuma. (2015). Aplikasi Asuhan Keperawatan Berdasarkan Diagnosa Medis dan Nanda Nic-Noc. Jogjakarta: Mediaction Publishing.

Arif Muttaqin, \& Kumala Sari. (2011). Asuhan Keperawatan Gangguan Sistem Perkemihan. Banjarmasin: Salemba Medika.

Caroline Bunker Rosdahl, \& Mary T Kowalski. (2015). Buku Ajar Keperawatan Dasar. Jakarta: Buku Kedokteran EGC.

Eko Prabowo, \& Andi Eka pranata. (2014). Buku Ajar Asuhan Keperawatan Sistem Perkemihan. Yogyakarta: Nuha Medika. 
Jurnal Media Keperawatan: Politeknik Kesehatan Makassar

Vol. 10 No. 022019

e-issn : 2622-0148, p-issn : 2087-0035

LeMone, P. (2016). Buku Ajar Keperawatan Medikal Bedah Ed.5,Vol.3. Jakarta: Buku Kedokteran EGC..

Padila. (2012). Buku Ajar : Keperawtan Medikal Bedah. Yogyakarta: Nuha Medika.

Toto Suharyanto, \& Abdul Madjid. (2009). Asuhan Keperawatan Pada Klien Dengan Gangguan Sistem Perkemihan. Jakarta Timur: CV. Trans Info Media. 